\title{
Organizational Conflict Management as Disputing Process The Problem of Social Escalation
}

\author{
CALVIN MORRILL \\ University of Arizona \\ CHERYL KING THOMAS \\ University of Minnesota
}

\begin{abstract}
In this article, organizational conflict management is conceived as a "disputing process" involving the social escalation from grievance stage to conflict and dispute stages. The Disputing Process Instrument (DPI) was designed as a way to study these phenomena quantitatively. Seven behaviors are represented in the instrument: conciliatory negotiation, third-party mobilization, overt retaliation, covert retaliation, toleration, avoidance, and discipline. The DPI demonstrated high reliability, content, discriminant, and construct validity relative to earlier conflict instruments. An empirical study of social escalation was conducted among peers with different strengths of informal relations in an electronics firm. The study results revealed that interpersonal problems among weakly tied peers are likely to be contained at the grievance stage using covert behaviors or to be socially escalated to disputes involving third parties. More strongly tied peers are likely to escalate their problems from grievances to dyadic confrontations only. These results have implications for understanding disparate results from earlier studies of peer conflict in organizations and for arguments regarding the introduction of external third-party conflict consulting in organizations.
\end{abstract}

$t$ has recently been proposed that the forms and conse-
quences of organizational conflict can be fruitfully studied
as behavioral processes embedded in larger social systems. Im-

Calvin Morrill is Assistant Professor of Communication and Sociology at the University of Arizona. Cheryl King Thomas is a Project Coordinator in the Division of Health Services Research and Policy at the University of Minnesota. Portions of this article are drawn from a master's thesis completed by the second author in the Department of Communication at the University of Arizona. An earlier version of this article was presented at the annual meeting of the International Communication Association in San Francisco, 1989. We thank Mark E. Adkins, Thomas S. Birk, Michael Burgoon, Edwin J. Dawson, Sally Jackson, Beth A. Le Poire, Deborah A. Newton, and Michael $\mathrm{J}$. Payne for valuable assistance in preparing the study and the manuscript. We also thank two anonymous $H C R$ reviewers for helpful comments on earlier drafts.

Human Communication Research, Vol. 18 No. 3, March $1992400-428$

- 1992 International Communication Association 
plicit in this view is the argument that communication studies of organizational conflict must move beyond the individual and dyadic levels to encompass organizational dimensions. Also implicit in such a view is the developmental nature of organizational conflict (Knapp, Putnam, \& Davis, 1988). Although these ideas are not new to communication theories of conflict (e.g., Folger \& Poole, 1984) or to interdisciplinary organizational studies of conflict (e.g., Pondy, 1967; White, 1961), organizational communication scholars have not systematically incorporated these orientations into their empirical work. This article argues that a more complete understanding of organizational conflict can be achieved by exploring different stages of the "disputing process" as it unfolds in organizational contexts.

Specifically, the authors draw on discussions of the disputing process in Nader and Todd (1978) and Morrill (1989) to conceptualize the phenomenon as entailing three stages: grievance expressions, conflict, and disputing. Mere classification does not motivate the adoption of this terminology. The movement from grievance to conflict to dispute has important consequences for the range of options and outcomes that aggrieved parties face. It thus allows the important issue of "social" escalation to be directly addressed. Social escalation is an important element of conflict because different levels of social escalation result in differential benefits and costs to organizations and their members (Eccles, 1985; Putnam \& Poole, 1987). In this framework, social escalation does not focus on perceptions of the stakes, the emotional states, or the number of issues between the principals (Deutsch, 1973; Pruit \& Rubin, 1986; Thomas, 1976). The present use of the concept shifts the problem of escalation beyond the interpersonal level to focus on the greater involvement of the social system of which conflict is a part, in essence, a widening of the scope of conflict (Schellenberg, 1982). Social escalation therefore need not be infused with positive or negative valences as in traditional conceptualizations. It can involve parties who may help to resolve or control hostilities as well as those who can exacerbate hostilities (Koch, 1974).

As a first step in rigorously studying the developmental and systemic nature of disputing in organizations, each of these stages was measured with a single instrument, the Disputing Process Instrument (DPI). This measurement instrument derives in part from previous conflict instruments and draws from sociological and anthropological literature on conflict in cross-cultural contexts. The DPI therefore taps into the larger system of which conflict is a part, including coalition 
formation, third-party intervention, and the use of discipline/ reward strategies. It was used to study the disputing process among peers with various strengths of relationships in a southwestern electronics firm, the objective being to provide a more complete picture of how disputing occurs in situ. Such a beginning should ultimately yield more theoretical insight into the contextual and developmental nature of grievances, conflicts, and disputes in organizations.

\section{THE CURRENT STATE OF RESEARCH ON ORGANIZATIONAL CONFLICT}

The recognition that interpersonal conflict is a pervasive and fundamental aspect of organizational life has led to a plethora of definitions of the phenomenon. Conceptualizations of conflict used in organizational research include references to incompatible interests, goals, values, and resources (Coser, 1964; Deutsch, 1973; Hocker \& Wilmot, 1985; Pondy, 1967; Putnam \& Wilson, 1982). Some researchers suggest that conflict only occurs when there is "opposing organizational action between parties which is not considered to be legitimate" (Clark, 1988, p. 153).

These concerns are implicit in numerous efforts to quantitatively measure organizational conflict via self-report instruments, most of which tend to emphasize what people do within dyadic conflict situations. Much of this concern originates in Blake and Mouton's (1964) "managerial grid" that was designed to measure individual predispositions toward transcontextual conflict management "styles." Blake and Mouton argued that conflict management styles could be measured along two managerial attitudes: concern for production and concern for people. This scheme resulted in five conflict-handling modes: forcing (pushing one's position onto that of an adversary without concern for his or her position), withdrawing (curtailing discussion of conflict with an adversary), smoothing (approaching an adversary in a conciliatory fashion), compromising (partially accepting an adversary's position), and problem solving or confronting (finding a mutually agreeable resolution that does not compromise either adversary's position). Thomas and Kilmann (1974) continued with the emphasis on the individual level of analysis by adding dimensions of concern for self and concern for others, also resulting in five styles of interpersonal conflict management: competing, collabo- 
rating, avoiding, accommodating, and compromising. Lawrence and Lorsch (1967) and Hall (1969) also proposed similar five-factor individual-level conflict style schemes drawn in part from Blake and Mouton's (1964) original formulations.

The untested content validity, low reliabilities, social desirability biases, scoring difficulties, and ideological biases regarding the most effective ways to handle conflict in early conflict instruments (WeiderHatfield, 1988; Womack, 1988) prompted communication and management scholars to develop more valid and reliable conflict instruments in the early 1980s. Putnam and Wilson (1982), for example, recognized that conflict management occurs as an exchange of communication strategies between principals. They also argued that the five conflict management styles reported by earlier researchers collapsed into three primary factors of nonconfrontation (avoiding or smoothing over discussion of a conflict), control (forcing one's position on an adversary through persistent arguing), and solution orientation (discussion of alternative conflict resolutions). These three dimensions formed the Organizational Communication Conflict Instrument (OCCI). Rahim (1983) developed the Rahim Organizational Conflict Inventory-II (ROCI-II), which was based directly on Blake and Mouton (1964). Here again, five styles were found: integrating/collaborating, obliging/accommodating, dominating/competing, avoiding/withdrawing, and compromising. Finally, Ross and DeWine (1988) focused on both the individual and dyadic levels, arguing that conflict management styles focus on self, individual, and others.

Despite the methodological advances and conceptual modifications in organizational conflict measurement since Blake and Mouton's (1964) original work, there have been only minor breaks from their personality-style approach. Recent work by communication scholars, however, explicitly suggests that the two-dimensional matrix that forms the basis of current conflict measurement instruments may not accurately conceptualize conflict management behaviors as they develop in organizational contexts (Riggs, 1983; Putnam \& Poole, 1987). Knapp et al. (1988) persuasively argued for the need to "refram[e] our thinking about the role of interpersonal conflict in organizations" (p. 425). To do so necessitates bridging the gap between conflict instrumentation research that stresses rigorous scale development for use in quantitative research and theoretical perspectives that focus on the behavior of conflict management as it develops in concrete organizational contexts. Such a bridge may be found in studies by anthro- 
pologists and sociologists of the disputing process in a variety of social contexts.

\section{THE DISPUTING PROCESS \\ IN ORGANIZATIONAL CONTEXT}

During the past 60 years, anthropologists and sociologists have compiled a wealth of knowledge about the ways in which people handle interpersonal grievances, conflicts, and disputes in a variety of societies. Nader and Todd (1978) summarized the anthropological research in this area:

Anthropologists have written about judges, councils, go-betweens, crossers, duelers, and so forth. They have also compared negotiation with mediation, arbitration, and adjudication techniques. Thus, we have a pretty fair idea of the range of variation in patterns ... relating to the management of disputes in specific societies. (p. 2)

Recent ethnographic research on organizational conflict has borrowed much from the anthropological record, stressing the processual and systemic nature of conflict (Bergman \& Volkema, 1989; Kolb \& Bartunek, 1992; Morrill, 1989). The thrust of this research has been behavioral: to understand conflict as a normative process contingent on the social context in which it occurs (e.g., Black, 1984, 1990). From this perspective, "grievance," "conflict," and "disputing" are stages in the disputing process that may or may not occur under particular social conditions. A grievance refers to a preconflict or first "volley" stage in which a person or group reacts to a real or perceived violation of a set of norms, rules, or individual or societal standards. Conflict involves the exchange of grievances ("volleys") either directly or indirectly between individuals or groups. Disputing occurs when conflicts draw third-party intervention and become a public matter. It should be noted that the stages in the disputing process do not necessarily form neat sequences. Aggrieved parties may escalate their complaints directly to the dispute stage if they never exchange grievances, or conflicts can de-escalate back to grievances if one party breaks off the fray.

The specific behaviors that people use to manage their grievances, conflicts, and disputes have been organized into a number of crosscultural typologies. Taken together these typologies appear to be based on three underlying behavioral dimensions: aggressiveness, 
authoritativeness, and observability. Aggressiveness refers to the degree to which an aggrieved party attempts to achieve his or her desired outcome at the expense of an opposing party at any stage in a disputing process (e.g., Bohannan, 1967; Koch, 1974; Roberts, 1979). Authoritativeness is known by the extent to which an aggrieved party attempts to impose an outcome at any stage in a disputing process using the resources their social position affords them (Black \& Baumgartner, 1983). Observability refers to the likelihood that the stages of a disputing process will be visible to any social audience (e.g., Baumgartner, 1988; Koch, 1974).

These three dimensions have particular relevance to organizational contexts. Several researchers have pointed to the impact that widely viewed acts may have on the culture or shared meanings in an organization (e.g., Pacanowsky \& O’Donnell-Trujillo, 1983). A classic formulation of these ideas is found in Goffman's (1959) conceptualization of organizations as systems of meaning held together with front stage and backstage interpersonal performances. In this sense, unobserved (covert) grievances are those that occur backstage where the performance of the grievance expression is less visible to the organizational "audience" (sometimes only to an audience of one: the target of the grievance), whereas observed (overt) grievances are those more accessible to the wider organizational audience. Observed grievances may therefore feed more directly into organizational culture than would unobserved grievances. Aggressiveness taps into the problem of order and predictability that every organization attempts to preserve to some degree (Strauss, 1978). In this sense, aggressiveness can be seen as a threat to such order in that it may disrupt the predictable routines of an organization. It may promote organizational change as well (Morrill, 1992). Aggressiveness also captures the earlier notion of assertiveness found in previous organizational conflict scales (Blake \& Mouton, 1964). Authoritativeness taps into formal organizational structure, including the ability to use discipline and reward strategies backed by the resources and legitimacy of one's organizational position. It should also be noted that these three dimensions differ from those found in Riggs's (1983) inductively derived conflict instrument that emphasizes two dimensions, flexibility and activity, which in themselves reflect more individual or dyadic-level communicator characteristics than features of organizational contexts. 
Fifteen behaviors representing observability, authoritativeness, and aggressiveness were culled from the anthropological and sociological literature on the disputing process:

1. Avoidance: Unilateral curtailment by an aggrieved party of all or some social interaction with an offender (Baumgartner, 1988; Furer-Haimendorf, 1967; Turnbull, 1965)

2. Commands: Directives between aggrieved parties to immediately and without question alter some aspect of each other's offensive behavior (Black \& Baumgartner, 1983; Morrill, 1989)

3. Conciliatory approaches: When aggrieved parties approach one another from postures of reason or moderation and ask each other to respond similarly (Baumgartner, 1984a; Van Maanen, 1988)

4. Covert discipline: Unilateral private punishment by an aggrieved superior of an offending subordinate with reference to a set of explicit conduct standards (Black, 1990; Kolb, 1988; Morrill, 1989)

5. Covert noncooperation: Intentional, private failures by an aggrieved party to perform behaviors expected of him or her in response to an offender's behavior (Baumgartner, 1984b)

6. Direct criticism: Direct, verbal attacks by an aggrieved party against an offender (Koch, 1974; Morrill, 1989, 1991a)

7. Informal counseling: When an aggrieved party advises an offender how he or she can return his or her behavior to some acceptable standard (Gibbs, 1963; Morrill, 1989, 1991b)

8. Negotiation: Attempts by aggrieved parties to engage each other in joint decision making to resolve a conflict in a mutually agreeable way (Barley, 1991; Bazerman \& Lewicki, 1983b; Gulliver, 1979).

9. Overt discipline: Public punishment (sometimes publicized via written or electronic media) of a subordinate offender by an aggrieved superior with reference to an explicit set of conduct standards (Black, 1990; Morrill, 1989; Patterson, 1982)

10. Overt noncooperation: Intentional public failure of an aggrieved party to perform behaviors expected of him or her in response to an offender's behavior (Baumgartner, 1984b)

11. Representative negotiation: Attempt by aggrieved parties to engage each other in negotiation through third parties (Black, 1990; Engel, 1978)

12. Secret complaining: When an aggrieved party complains to a third party about the behavior of an offender without the offender's knowledge (Baumgartner, 1984a)

13. Settlement: Referral of a grievance by an aggrieved party to a relatively nonpartisan third party for resolution (Black \& Baumgartner, 1983; Galtung, 1965; Morrill, 1989)

14. Sabotage: Aggressive covert retaliation by an aggrieved party against an offender (Baumgartner, 1984b) 
15. Toleration: Endurance and inaction by an aggrieved party against an offender (Baumgartner, 1984a; Felstiner, 1974; Merry, 1979).

These behaviors are represented graphically on continua of aggressiveness, authoritativeness, and observability in Figure 1. Following the definitions offered here, the most aggressive behaviors are represented by commands and sabotage. Moderately aggressive behaviors would be noncooperation and discipline. The remainder of the behaviors fall between moderate and low aggressiveness. Highly authoritative behaviors are represented by commands, discipline, and settlement. Counseling represents a moderately authoritative behavior; the remaining behaviors represent less authoritative behaviors. Highly observable behaviors are represented by overt discipline and overt noncooperation. Moderately observable behaviors, because they involve third parties and because of their confrontational nature between the principals involved, are represented by negotiation, settlement, commands, conciliatory approaches, direct criticism, counseling, and representative negotiation. Less visible behaviors would be avoidance, sabotage, secret complaining, and toleration.

It should also be noted that these 15 behaviors tend to focus on two stages of the disputing process that have been less systematically tapped by current conflict instruments, namely, the grievance and dispute stages. Thus the DPI could be used in a complementary manner with the more proven conflict instruments, such as Blake and Mouton's (1964) managerial grid, Putnam and Wilson's (1982) OCCI, or Rahim's (1983) ROCI-II. At the same time, the behaviors overlap in six instances, with behaviors contained in these conflict instruments. The overlaps between the 15 behaviors and these three instruments are summarized in Figure 2. Behaviors that involve third parties, drawing on one's authority position in the formal organizational structure (discipline), and informal counseling, however, do not overlap.

\section{THE DEVELOPMENT OF THE DPI}

Initial Scale Development

Items were generated to represent each of the 15 behaviors described earlier. Independent judges (advanced graduate students) 


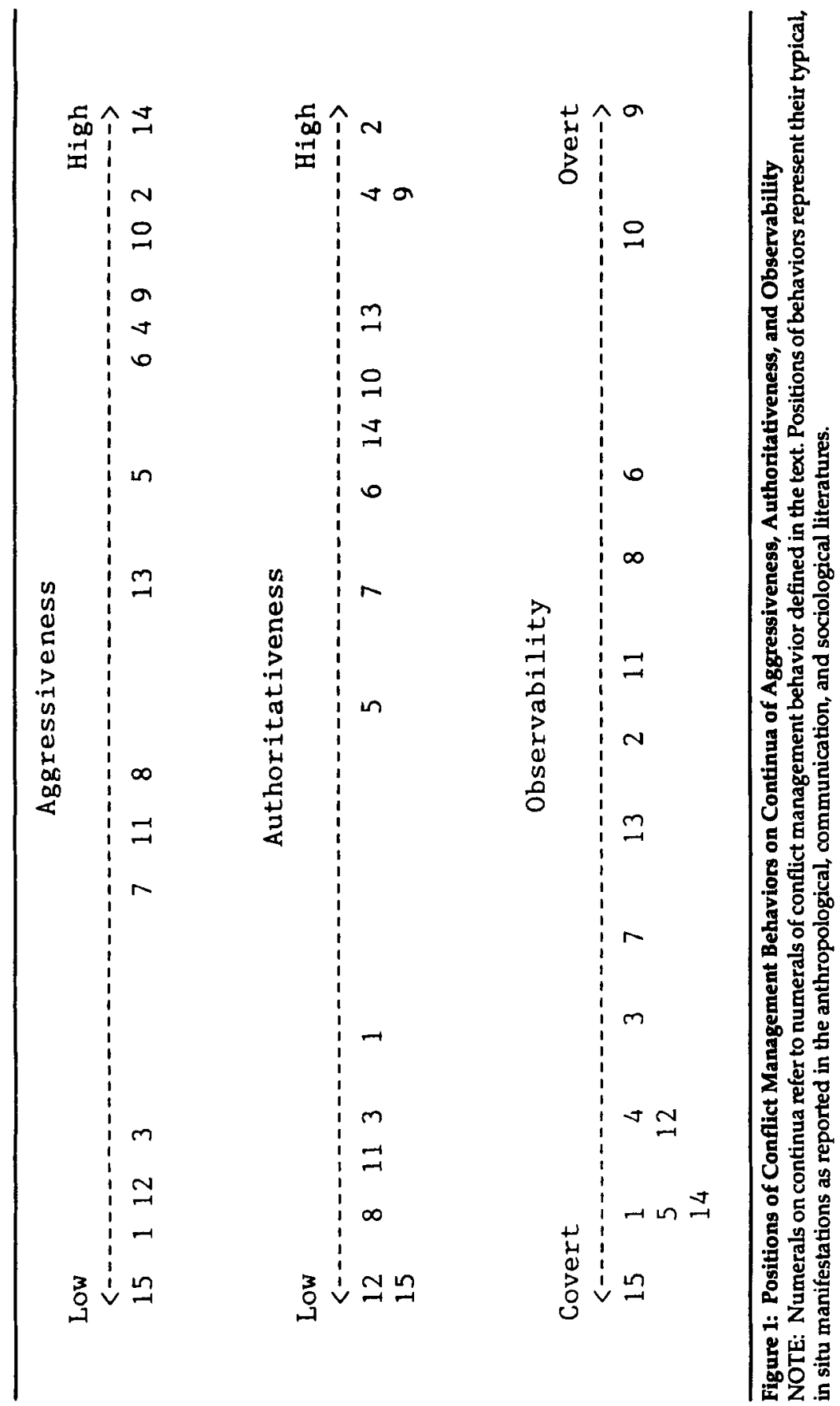




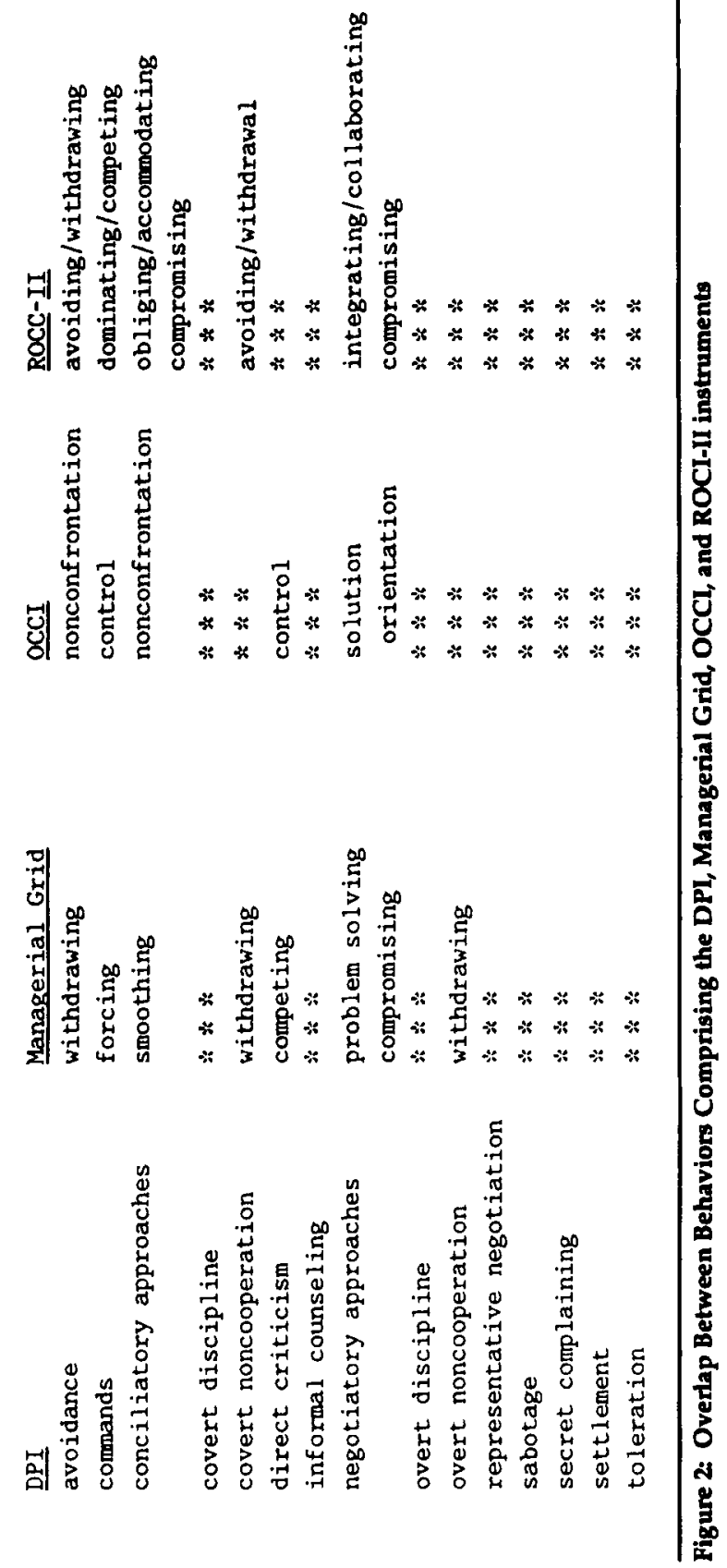


drawn from the Communication Department at the University of Arizona sorted an initial pool of 59 items into the 15 types. After the initial sorting, items were rewritten, added, or deleted to achieve face validity and to generate a pool of 90 items -6 items for each of the 15 behaviors.

Currently employed adults $(N=619)$ drawn from a county jury room in southern Arizona completed three forms of the DPI to establish initial validity and reliability of the instrument. Potential jurors are randomly selected from the population of registered voters and licensed drivers in the county and thus serve as a desirable sampling frame for instrument construction. For the combined samples of all developmental phases of the DPI (including those for Forms D and E, discussed later), a nearly equal number of men and women participated. Three quarters of the sample was between 21 and 50 years of age and had more than 10 years' work experience but less than 10 years' supervisory experience of some kind. About one quarter of the respondents described themselves as serving in upper management, one half in middle management, and the rest in lower management positions. Although information was not systematically collected regarding the types of organizations in which people worked, the typical diversity of occupations represented in jury selection increased the likelihood that a large variety of organizations were represented in the developmental stages of the research.

Respondents were asked, using 5-point Likert-type scales, to indicate whether they (1) never, (2) seldom, (3) sometimes, (4) often, or (5) always used the grievance expression represented by the item the last few times when they had a complaint or objection about the behavior of a specific co-worker. To improve recall, respondents were asked to complete the questionnaire with one specific co-worker (or subordinate, in the case of the Discipline subscale) in mind and to think of an objection or complaint that they had had against that person within the previous 6 months.

At each stage of the scale development, a principal components factor analysis with unities inserted in the diagonal was used. After orthogonal Kaiser varimax rotation, items were retained for the estimated factor solution if they had a primary loading of greater than .50 and no secondary loading greater than $30 \%$ of the primary loading. Additionally, a factor was retained at each developmental stage for the estimated solution only if it contained more than three primary 
loading items, demonstrated an eigenvalue greater than 1.5, and accounted for satisfactory incremental variance based on Cattell's (1966) scree test. The factor also must have demonstrated a reliability coefficient of greater than .70. In addition to the principal components analysis, a principal axis factor analysis with squared multiple correlations as the estimate of the commonalities was used to extract fewer factors, thus giving a more conservative factor solution estimate. After three stages, both the principal components and principal axis analyses revealed a five-factor solution: Confrontation, Third-Party Mobilization, Covert Retaliation, Toleration, and Discipline. Items originally representative of direct criticism, negotiation, informal counseling, and conciliatory approaches collapsed into a Confrontation factor. The Third-Party Mobilization factor was composed of items characteristic of representative negotiation and settlement. The Covert Retaliation factor consisted of sabotage and covert noncooperation items. Surprisingly, one direct criticism item also loaded on to this factor, probably due to unclear wording of the item. Toleration was composed of toleration items and, also surprisingly, a conciliatory approach item, again probably due to unclear item wording. Items originally categorized as overt discipline and covert discipline collapsed into one Discipline factor. Finally, authoritative commands, avoidance, and secret complaining items did not emerge in the factor solutions. From this analysis, 38 items were retained for Form D: 12 confrontation items, 9 third-party mobilization items, 5 sabotage items, 4 toleration items, and 8 discipline items.

Establishing Discriminant Validity, Construct Validity, and Reliability

Currently employed adults $(N=211)$ drawn from the same collection site completed Form D of the DPI, the Putnam-Wilson (1982) Organizational Communication Conflict Instrument, and the CrowneMarlowe (1964) Social Desirability Scale.

Principal components and principal axis factor analyses were performed to confirm the factor structure of the DPI. The same five-factor solution was found; however, two additional items were deleted due to their failure to meet the previously described criteria for retaining items from the factor solution. 


\section{Discriminant Validity}

To determine whether the final items retained from the factor analysis could also discriminate high scorers from low scorers, phi coefficients were computed for each of the items. The phi coefficient measures the strength of relationship between item scores and the total scores of the dimension of which that item is a part. If an item has high discriminatory power, respondents who score high on that item should score high on that dimension, and respondents who score low on that item should score low on that dimension. Items retained from the phi test demonstrated a phi greater than .50 .

The items composing the Covert Retaliation factor provided relatively poor discriminatory power between low and high scorers on that factor due in part to poor wording. One item from the Third-Party Mobilization factor and three items from the Discipline factor lacked satisfactory discriminatory power and were deleted.

After these deletions, alpha coefficients were calculated for the four remaining dimensions. All remaining dimensions at this stage in the instrument development demonstrated satisfactory reliabilities of .75 or above (Third-Party Mobilization $=.92$, Confrontation $=.91$, Toleration $=.75$, and Discipline $=.80$ ).

In addition to determining whether each factor of the DPI could discriminate high scorers from low scorers, interscale correlations were calculated to determine whether each of the four factors of the DPI were theoretically independent. All Pearson product-moment correlations were very low, including several near-zero and negative correlations (see Table 1). Thus independence and discriminant validity were supported.

Social desirability response bias is another important aspect of determining the discriminant validity of conflict-related instruments (Thomas \& Kilmann, 1975). Therefore, each of the DPI dimensions was correlated with the Social Desirability Scale (Crowne \& Marlowe, 1964) to determine whether people had responded to DPI items in ways they believed appropriate for grievance expression. Reliability analysis of the Social Desirability Scale revealed a coefficient alpha of .83. The Third-Party Mobilization, Toleration and Discipline factors had slight negative correlations with the Social Desirability Scale, and the Confrontation factor had a low correlation (see Table 1). These results indicate that the DPI has slight desirability biases. Tests of item desirability within the DPI were not conducted. 
TABLE 1

Pearson Product-Moment Correlations Between the Factors of the DPI, Form D, OCCI, and Social Desirability Instruments

\begin{tabular}{lcccc}
\hline \hline & \multicolumn{5}{c}{ DPI Scales } \\
\cline { 2 - 5 } Instrument & Third Party & Confrontation & Toleration & Discipline \\
\hline DPI & - & & & \\
Third Party & -.08 & -.08 & $.20^{*}$ & .04 \\
Confrontation & $.20^{*}$ & $-.36^{*}$ & $-.36^{*}$ & $.35^{*}$ \\
Toleration & .04 & $.35^{*}$ & $-.18^{*}$ & $-.19^{*}$ \\
Discipline & & & & - \\
OCCI & .11 & $.24^{*}$ & -.10 & $.16^{*}$ \\
Control & $.15^{*}$ & $.41^{*}$ & .00 & $.17^{*}$ \\
Solution Orientation & $.19^{*}$ & $-.31^{*}$ & $.50^{*}$ & $-.20^{*}$ \\
Nonconfrontation & -.19 & .15 & -.25 & -.01 \\
Social Desirability Scale & & .15 & & \\
\hline
\end{tabular}

${ }^{*} p<.05$.

Construct Validity and Reliability

As discussed previously, the Putnam-Wilson (1982) OCCI suggests that individuals respond to conflict situations by using nonconfrontation, control, and solution-orientation strategies. According to Putnam and Wilson's (1982) definition of nonconfrontation, there should be a moderate to high correlation between the OCCI Nonconfrontation factor and the DPI Toleration factor, a lower, moderate correlation between Nonconfrontation and the DPI Third-Party Mobilization factor, and near-zero to negative correlations between Nonconfrontation and the DPI Confrontation and Discipline factors. Putnam and Wilson's (1982) Solution Orientation factor should demonstrate a moderate to high correlation with the DPI Confrontation factor, a low to moderate correlation with the DPI Third-Party Mobilization factor, and slight correlations with the DPI Toleration and Discipline factors. The third factor of the OCCI, Control, should demonstrate moderate to high correlations with the Discipline and Confrontation factors of the DPI, a low correlation with the DPI Third-Party Mobilization factor, and a near-zero to negative correlation with the DPI Toleration factor.

A reliability analysis of the OCCI revealed alpha coefficients of .90 for the Nonconfrontation dimension, .88 for the Solution Orientation 
dimension, and .77 for the Control dimension. Pearson productmoment correlations for each of the OCCI and DPI factors support the trend of the previously outlined predictions. Nonconfrontation had a moderate correlation with Toleration (.50), a low correlation with Third-Party Mobilization (.19), and negative correlations with Confrontation (-.31) and Discipline (-.20). Solution Orientation had a moderate correlation with Confrontation (.41), low correlations with Third-Party Mobilization (.15) and Discipline (.17), and no correlation with Toleration (.00). Control had a low to moderate correlation with Confrontation (.24), low correlations with Third-Party Mobilization (.11) and Discipline (.16), and a low negative correlation with Toleration $(-.10)$.

The DPI, therefore, correlates with theoretically relevant constructs and does not correlate with theoretically irrelevant constructs. Thus the construct validity of the DPI is supported.

\section{Further Refinement of the DPI}

As mentioned earlier, the Covert Retaliation factor of the DPI only provided relatively poor discrimination of high from low scorers. Moreover, Avoidance, Commands, and Direct Criticism factors did not emerge from previous factor analyses. Because of mounting ethnographic evidence for the prevalence and distinctiveness of these behaviors in organizations (Barley, 1991; Morrill, 1989) and high reliabilities for Nonconfrontation factors in previous scales (Putnam \& Wilson, 1982), another attempt was made to measure these behaviors. Covert retaliation, avoidance, authoritative command, and direct criticism items from Form $D$ were rewritten to comprise a fifth form, Form E. The overall similarity of Forms $D$ and $E$ suggests that the tests of validity and reliability performed on Form $D$ would apply to Form $E$.

A random sample of currently employed adults $(N=222)$ at the same data collection site completed Form E. A principal components analysis revealed a seven-factor solution (the original behaviors on which they are based are given in parentheses):

1. Avoidance: Unilateral curtailment by an aggrieved party of all or some social interaction with an offender (avoidance)

2. Conciliatory Negotiation: When aggrieved parties approach one another from postures of reason or moderation, seeking to engage each other in discussion to reconcile grievances in a mutually acceptable way (conciliatory approaches, negotiation) 
3. Covert Retaliation: Secret, aggressive action by an aggrieved party to inconvenience an offender (covert noncooperation, sabotage)

4. Discipline: Covert or overt punishment of a subordinate offender by an aggrieved superior with reference to a set of explicit standards of conduct (covert and overt discipline)

5. Overt Retaliation: Direct, aggressive criticism by an aggrieved party of an offender's behavior (commands, direct criticism)

6. Third-Party Mobilization: Referral of a grievance by an aggrieved party to a third party either for representation against an opponent or for settlement (representative negotiation, settlement)

7. Toleration: Endurance and inaction by an aggrieved party against an offender (toleration).

Four of the five factors that emerged from Form D (Covert Retaliation, Discipline, Third-Party Mobilization, and Toleration) emerged in the analysis of Form E. Confrontation items dichotomized into Conciliatory Negotiation and Overt Retaliation, and Avoidance emerged as a separate factor. Table 2 reports the percentage variance accounted for, eigenvalues, and alphas for each DPI factor as well as the means, standard deviations, and factor loadings for each item on Form E. ${ }^{1}$ The final factors are graphically represented in Figure 3 by their location in the three-dimensional theoretical space composed of aggressiveness, observability, and authoritativeness.

\section{RELATIONAL TIES AND THE DISPUTING PROCESS IN ORGANIZATIONAL CONTEXT}

As mentioned at the outset, an important theoretical question that the DPI allows one to study is the problem of escalation from the grievance to the dispute stage. The theoretical framework of the present work emphasizes that the disputing process is contingent on social aspects of the organizational setting in which it occurs (e.g., Black, $1984,1990)$. This resonates with recent research on organizational conflict by communication scholars. A review of the conflict instruments literature, for example, revealed that much of the variance in conflict styles can be predicted by relationships between the principals, such as whether they are in hierarchical or peer relations with one another (Putnam \& Poole, 1987). Using their OCCI instrument, Putnam and Wilson (1982, cited in Putnam \& Poole, 1987) found that 


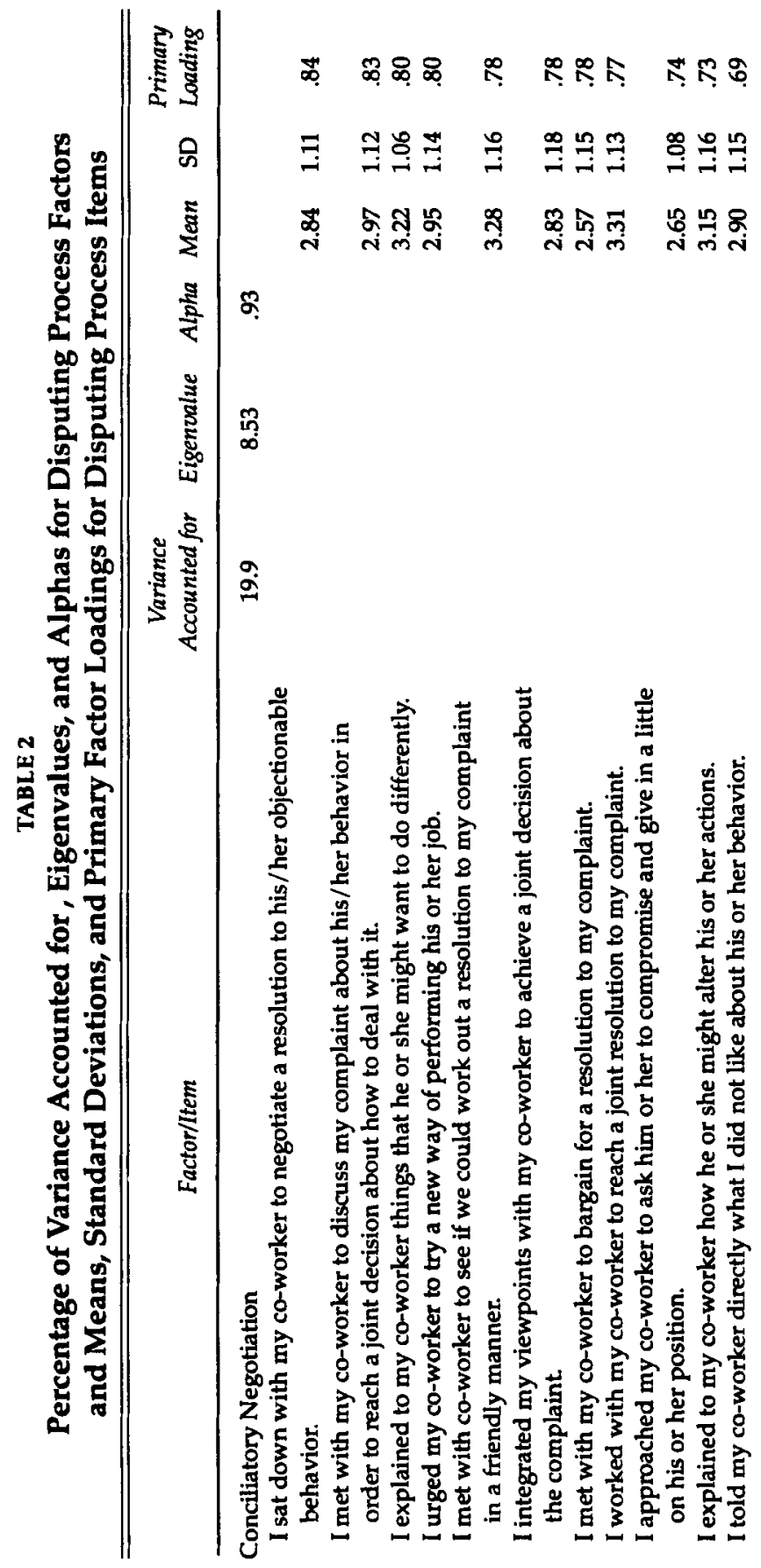




$$
\begin{aligned}
& \text { ஓ ๘ }
\end{aligned}
$$

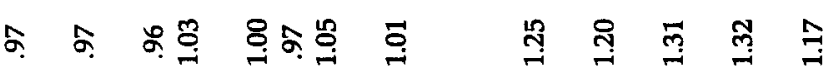

$$
\begin{aligned}
& \text { @্ }
\end{aligned}
$$

ร

今.

$\overline{+}$

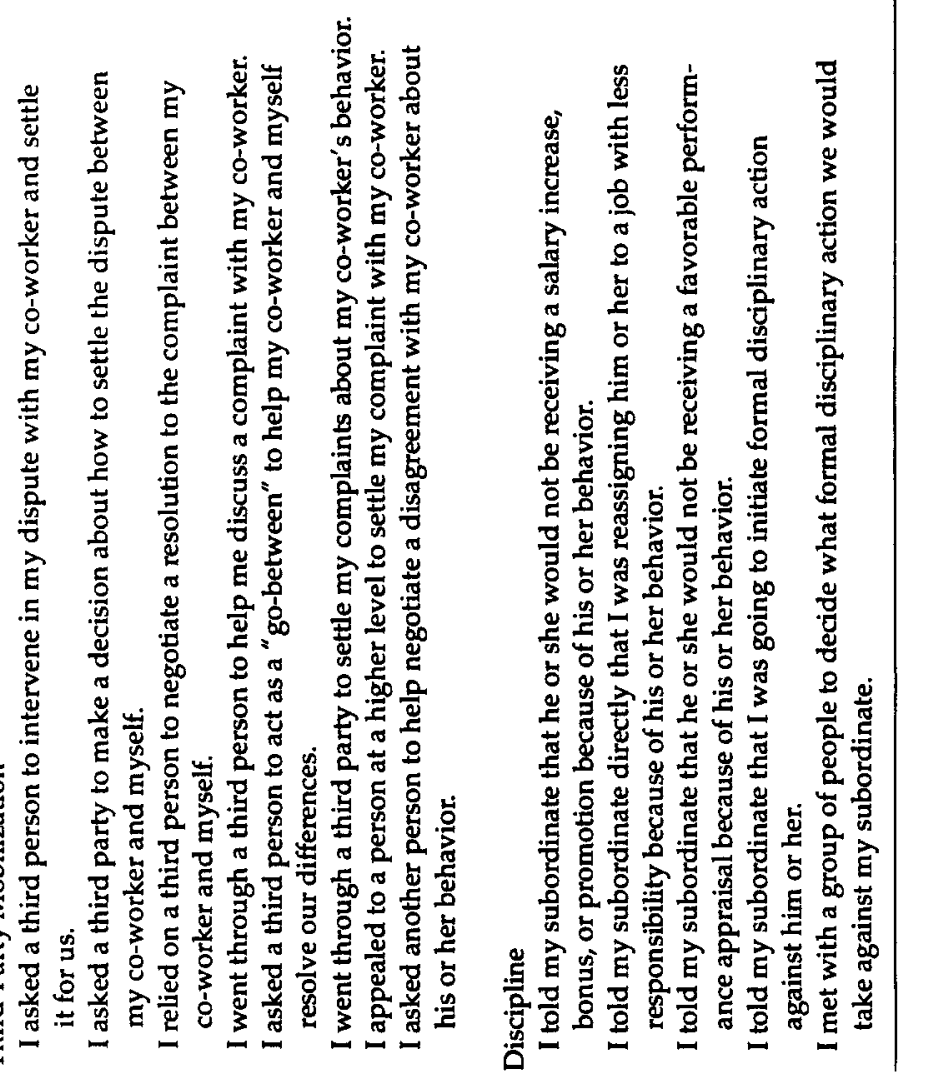




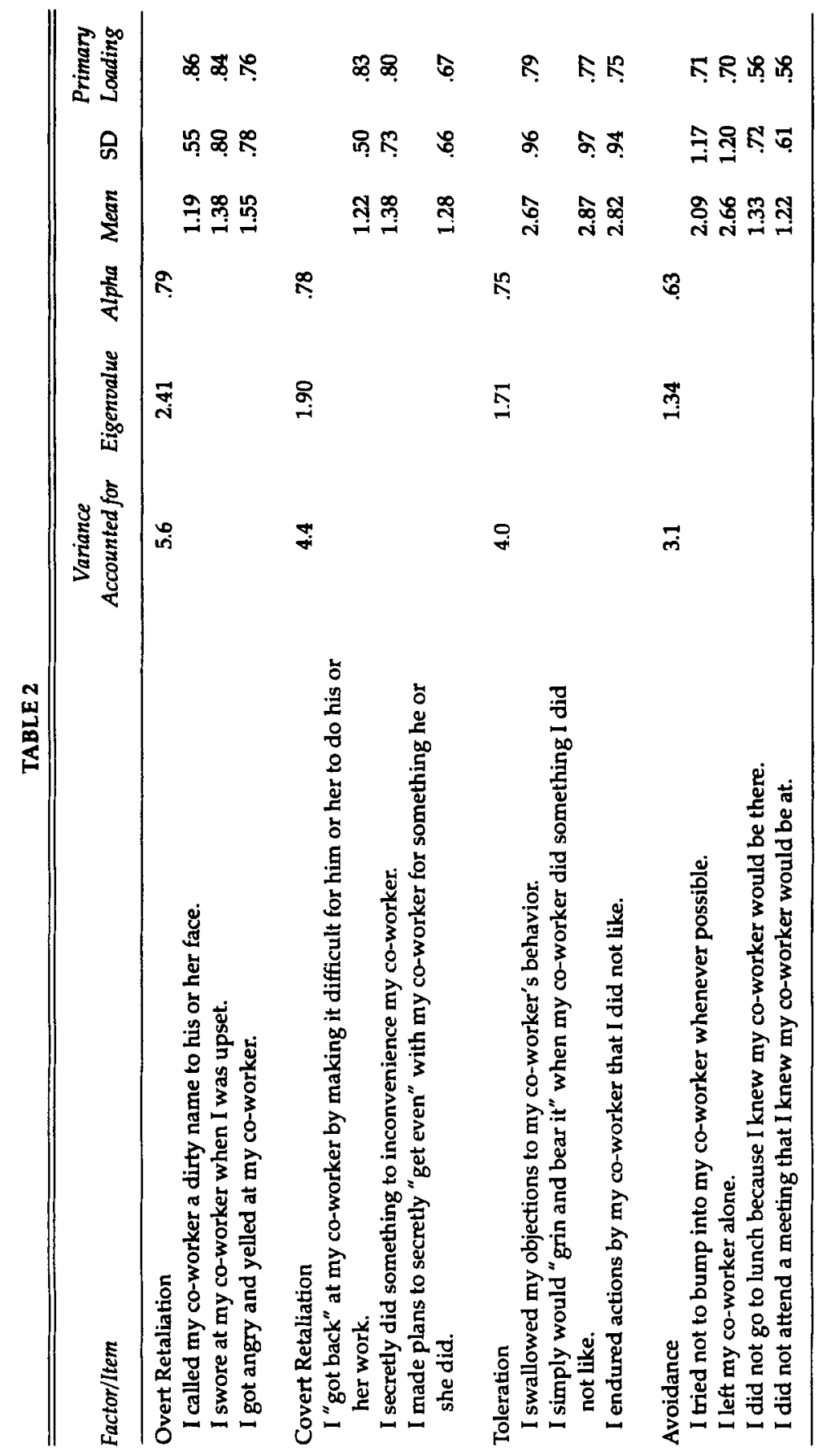




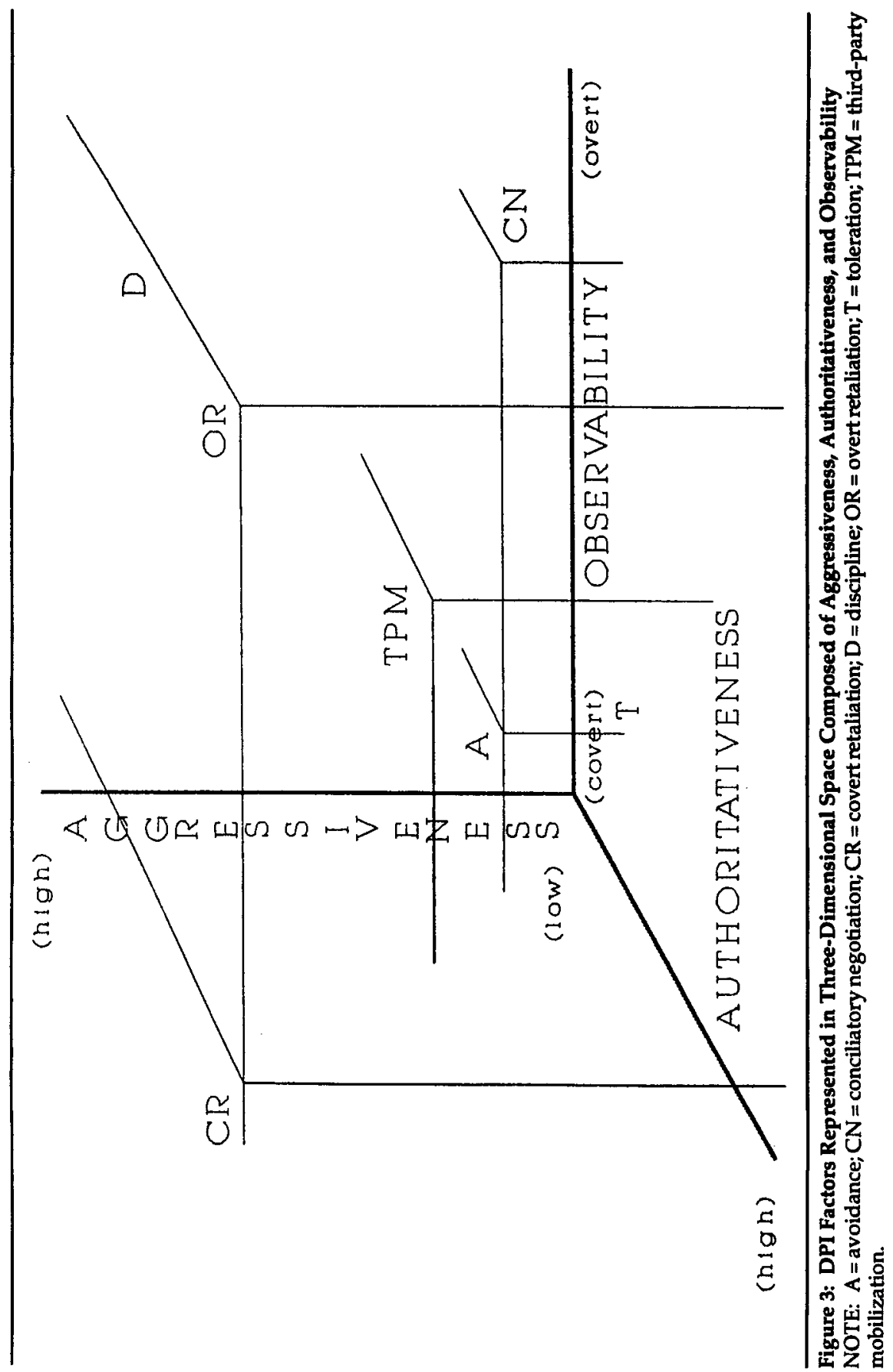


subordinates tended to confront or smooth conflicts with superiors, superiors tended to force conflict outcomes on subordinates, and peers tended to avoid or smooth conflicts with one another. Using his ROCI-II instrument, Rahim (1986, cited in Putnam \& Poole, 1986) found that subordinates tended to smooth over conflicts with superiors, superiors tended to confront subordinates, and peers tended to compromise with each other. Although the vertical relationship between co-workers is certainly important in predicting conflict, studies drawn from the same literatures on which the DPI is based and recent organizational research suggest that informal social ties also predict social escalation (Gluckman, 1956/1969; Kapferer, 1972; Koch, 1974; Nelson, 1989).

Baumgartner (1988), for example, argued that less observable interpersonal grievance expressions, such as avoidance, toleration, and noncooperation, are especially likely in settings where aggrieved parties and offenders have weak relational ties with one another, that is, have little contact or few emotional bonds with one another (Granovetter, 1973). Adversaries can more easily avoid or inconvenience individuals with whom they do not have emotional investments or tolerate an offense with the expectation of easy avoidance. At the same time, principals with weak ties are more likely to invoke third parties who can facilitate their communication leading to conflict settlement should they not obtain satisfaction from covert means (Black \& Baumgartner, 1983). When principals have more invested in their social ties, they are more likely to seek mutually accommodating solutions to their grievances via negotiation (Black, 1990; Gulliver, 1979) or more aggressive forms of confrontation (Merry, 1979). Informal social ties between principals may therefore help explain when grievances will escalate beyond dyadic conflicts to disputes. Such ties may also help explain the conditions under which peers will compromise in conflict situations (as in Rahim, 1986) or avoid and smooth over conflicts (as in Putnam \& Wilson, 1982). Based on these theories, a single hypothesis was advanced:

H1: Aggrieved parties who express their grievance strategies covertly and escalate their grievances into disputes will have weaker social ties with their offenders than will aggrieved parties who use overt strategies.

A study was designed to test the ability of the DPI to test these hypotheses. Employees $(n=57)$ at an electronics firm in southern Arizona completed Form E of the DPI. Prior to doing so, respondents 
were requested to think of grievances that they had had over the past 6 months against a co-worker peer with whom they had no tie or who they considered (a) an acquaintance, (b) a friend, or (c) a close friend. This simple one-item scale was derived from Granovetter (1973) and a meta-analysis of empirical investigations of tie strength conducted by Marsden and Campbell (1984).

Granovetter (1973) suggested that a social tie can be conceived as the "combination of the amount of time, the emotional intensity (closeness), the intimacy (mutual confiding), and the reciprocal services" between individuals or groups (p. 1361). However, Marsden and Campbell (1984) argued that these dimensions are highly intracorrelated and that global emotional intensity is the least contaminated measure of informal tie strength and probably undergirds the other dimensions. Although this measure loses some of the richness of Granovetter's (1973) conceptualization, it does parsimoniously capture an essential feature of his definition.

The majority of organizational members in the study were male (59\%), high school educated (74\%), 21-40 years of age, and with from 1 to 5 years of tenure with the firm. ${ }^{2}$ Only $8(14 \%)$ of the respondents held supervisory roles, which eliminated the possibility of using the Discipline subscale. Hypothesis 1 was tested with stepwise multiple regression to determine the relative impact of the DPI factors on tie strength of organizational members. Criteria for model selection were a significant $F(p<.05)$ for the overall model and a significant $F$ for the increment in variation accounted for by each new variable entered and retained in the model.

Hypothesis 1 was partially supported. Conciliatory Negotiation and Overt Retaliation were associated with greater tie strength. ThirdParty Mobilization, Avoidance, and Covert Retaliation were associated with weaker tie strength (see Table 3). These five factors significantly predicted tie strength, overall $(F[5,52]=5.74, p<.01, R=.49)$.

\section{DISCUSSION}

This research was intended to provide a more complete picture of interpersonal conflict as it occurs in organizational contexts. This endeavor was judged successful on several fronts. First, use of the concept "disputing process" advances an approach that emphasizes the behavioral, processual, and system-embedded nature of interper- 
TABLE 3

Stepwise Multiple Regression of Strength of Tie on Disputing Process Factors

\begin{tabular}{lrccrc}
\hline & \multicolumn{5}{c}{ Strength of Tie } \\
\cline { 2 - 6 } Order of Entry of Factor & $\mathrm{r}$ & $\mathrm{R}$ & RSQ Change & $\mathrm{b}$ & F Ratio \\
\hline Conciliatory Negotiation & .61 & .38 & .38 & .32 & $33.71^{*}$ \\
Third-Party Mobilization & -.47 & .43 & .05 & -.10 & $20.37^{*}$ \\
Avoidance & -.28 & .46 & .03 & -.11 & $15.05^{*}$ \\
Covert Retaliation & -.31 & .48 & .02 & -.13 & $12.00^{*}$ \\
Overt Retaliation & .13 & .49 & .01 & .06 & $5.74^{*}$ \\
\hline
\end{tabular}

${ }^{*} p<.01$.

sonal conflict in organizations. Such an approach is particularly useful for the study of social escalation, the process by which conflicts enlarge in scope and involve more of their social audience as participants and observers. Second, the research showed the viability of measuring the disputing process through the psychometric development of the DPI, which demonstrates relatively (to previous conflict instruments) high validity and reliability. Third, the DPI was used to assess the choices that organizational members make in escalating their grievances to disputes in differential relational ties embedded in an actual organizational context. The results from this development of and research with the DPI suggest several paths for future research.

One such area deserving immediate attention concerns the limited tests of social desirability and the DPI conducted in the present investigation. Because tests of item desirability within the DPI were not conducted, future studies might either test item desirability or concurrent validity of the instrument with inductive descriptions of similar types of disputing processes drawn from particular organizational contexts. The goals of such research would be twofold. Such investigations could further examine the validity of the DPI as well as enhance our understanding of the normative bases for conflict management variation.

Another area of research to which studies with the DPI might contribute relates to investigations of conflict management in peer and hierarchical relationships. Current findings are somewhat consistent for conflict management within superior-subordinate relationships but inconsistent for peer relationships. Results with the DPI indicate that variation in peer-related conflict management varies with the strength of informal relations among principals. Peers with 
strong ties are the most likely to escalate their grievances to the conflict stage and handle them via conciliatory negotiation, with the next most likely conflict management strategy being overt retaliation. Peers with weak ties to one another typically do not escalate their grievances to the dispute stage; they either handle them covertly themselves or engage the help of third parties.

These results also conform to theories of conflict management among intimates. Simmel (1908/1955) noted long ago that "the most firmly grounded relation may take a chance at discord, whereas good and moral but less deeply rooted relationships apparently follow a much more harmonious and conflictless course" (p. 47). The present findings also conform to more recent empirical research on conflict management among intimates. Fitzpatrick (1988), for example, found that marital couples who were least intimate in terms of emotional closeness and interdependence were the least likely to engage in confrontation to manage conflict. More intimate couples engaged in a range of confrontation. Fitzpatrick (1988) also reported that confrontation is so antithetical to the way in which less intimate couples manage conflict, that in counseling sessions they often needed to be taught how to openly handle problems that arose between them.

This last finding from the relational literature has important implications for organizational contexts in relation to the present findings. Over 20 years ago, business scholars began to argue that negotiation facilitated by third parties can be a most productive and efficient way to handle organizational conflict (Prien, 1987; Walton, 1969). In the early 1980s, Supreme Court Justice Warren Burger argued that third parties other than the courts must become involved to aid in the management of organizational conflict (Bazerman \& Lewicki, 1983a). Such arguments have produced recent empirical investigations of the effectiveness of mediation, representative negotiation, and arbitration in organizations (Bazerman \& Lewicki, 1983b). Yet little is known about the receptivity of such practices by organizational members themselves. Anecdotal evidence from some scholars indicates that corporate executives, at least, are very unreceptive to internal or external third parties in their organizations (Raiffa, 1982). Ethnographic evidence indicates that such receptivity may vary across firms and within firms (Morrill, 1991a, 1992).

The present research may provide some clues to the receptivity of third parties who could facilitate organizational disputing processes among peers with more satisfactory outcomes for the parties involved 
and their organizations. Ironically, principals without strong ties to one another, who are most likely to avoid each other but who are also likely to escalate their grievances to disputes (with the enlistment of third parties) may be the most receptive to external third-party intervention (despite such principals' claims otherwise; Morrill, 1991b). The unwillingness of weakly tied principals to escalate their grievances to conflicts could be because they will only confront one another in the presence of third parties who can help define the "rules of the game" for dispute handling. Following this logic, those principals who regularly engage dyadic conflict management may be the least receptive to external third-party intervention because they have welldefined rules of confrontation. Such speculations only begin to suggest the future research directions in which conceptualizing organizational conflict management as a disputing process may lead.

Another direction could lead to studies of escalation in organizational hierarchies. Baumgartner (1984b), for example, theorized that covert retaliation is likely when great power, wealth, or authority discrepancies exist between aggrieved social subordinates and offending superiors. Investigating subordinate grievances with superiors of immediate and higher ranks might suggest the authority threshold at which point subordinates are most likely to express their covert grievances aggressively and when they will escalate grievances to the conflict and dispute stages.

Such escalation might also vary with the duration of the problem (Nader \& Todd, 1978). Holding constant the authority distance between a subordinate and a superior, for example, subordinates might first opt for less aggressive nonverbal grievance expressions, such as avoidance and toleration as Putnam and Wilson (1982) found, and then opt for more aggressive confrontational disputing strategies if they did not initially obtain redress. Superiors might first opt for toleration and then proceed directly to some form of discipline.

Beyond its scientific interest in the area of conflict management, studying disputing processes in organizations with the DPI might also have practical applications for those organizations wishing to assess the relationship between disputing and other core organizational processes, such as innovation. Kanter (1983), for instance, suggested that communicative problem solving, which integrates organizational members into productive relations ("win-win" conflict management, represented by conciliatory negotiation in the DPI; 
Putnam \& Wilson, 1982), may be one key to sustaining innovation in organizations. If less integrative behaviors, such as downward disciplinary and tolerant upward grievance expressions, predominate in hierarchies (Morrill, 1989), organizations whose productivity depends on constant innovation may want to consider relaxing their authority structures to allow dyadic conflict management behaviors to evolve. Similar applications might be used in designing different departments within large organizations. For example, research and development departments might opt for conditions that encourage conciliatory negotiation, or departments with ongoing overt retaliatory feuds might be structured more hierarchically to induce resolution through discipline (e.g., Perrow, 1986, pp. 36-40). Such applications are suggestive of the possibilities that studying the disputing process could have for organizational practice. Suffice it to say that research on the disputing process in organizations could continue the integration of the study of organizational conflict management with mainstream concerns in organizational research and practice.

\section{NOTES}

1. A phi coefficient test revealed moderate discriminant validity for all of the reworded items in the Covert Retaliation and Overt Retaliation factors and the avoidance items for Form E. Secondary factor loadings are available from the first author on request.

2. Demographic information derives from a communication audit completed simultaneously with the disputing study on the same set of employees.

\section{REFERENCES}

Barley, S. R. (1991). Contextualizing conflict: Notes on the anthropology of disputes and negotiations. In M. H. Bazerman, R. J. Lewicki, \& B. H. Sheppard (Eds.), Research on negotiation in organizations (Vol. 3, pp. 165-203). Greenwich, CT: JAI.

Baumgartner, M. P. (1984a). Social control in suburbia. In D. Black (Ed.), Toward a general theory of social control: Vol. 1. Fundamentals (pp. 303-345). Orlando, FL: Academic Press.

Baumgartner, M. P. (1984b). Social control from below. In D. Black (Ed.), Toward a general theory of social control: Vol. 2. Selected problems (pp. 79-103). Orlando, FL: Academic Press.

Baumgartner, M. P. (1988). The moral of order of a suburb. New York: Oxford University Press. 
Bazerman, M. H., \& Lewicki, R. J. (1983a). Studying organizational negotiations: Implications for future research. In M. H. Bazerman \& R. J. Lewicki (Eds.), Negotiating in organizations (pp. 377-386). Beverly Hills, CA: Sage.

Bazerman, M. H., \& Lewicki, R. J. (Eds.). (1983b). Negotiating in organizations. Beverly Hills, CA: Sage.

Bergman, T. J., \& Volkema, R. J. (1989). Understanding and managing interpersonal conflict at work: Its issues, interactive processes, and consequences. In M. A. Rahim (Ed.), Managing conflict: An interdisciplinary approach (pp. 7-19). New York: Praeger.

Black, D. (Ed.). (1984). Toward a general theory of social control. Orlando, FL: Academic Press.

Black, D. (1988). Sociological justice. New York: Oxford University Press.

Black, D. (1990). The elementary forms of conflict management. In New School of Justice Studies (Ed.), New directions in the study of law, justice and social control (pp. 43-69). New York: Plenum.

Black, D., \& Baumgartner, M. P. (1983). Toward a general theory of the third party. In K. O. Boyum \& L. Mather (Eds.), Empirical theories about courts (pp. 84-114). New York: Longman.

Blake, R. R., \& Mouton, J. S. (1964). The managerial grid. Houston: Gulf.

Bohannan, P. (1967). Law and warfare: studies in the anthropology of conflict. Austin: University of Texas Press.

Cattell, R. B. (1966). The scree test for the number of factors. Multivariate Behavioral Research, 1, 245-276.

Clark, J. (1988). Presidential address on the importance of our understanding organizational conflict. Sociological Quarterly, 29, 149-161.

Coser, L. A. (1964). The functions of social conflict. New York: Free Press.

Crowne, D. P., \& Marlowe, D. (1964). The approval motive. New York: Wiley.

Deutsch, M. (1973). The resolution of conflict: Constructive and destructive processes. New Haven, CT: Yale University Press.

Eccles, R. G. (1985). The transfer pricing problem. Cambridge, MA: Harvard University Press.

Engel, D. M. (1978). Code and custom in a Thai provincial court: The interaction of formal and informal systems of justice. Tucson: University of Arizona Press.

Felstiner, W.L.F. (1974). Influences of social organization on dispute processing. Law and Society Review, 9, 63-94.

Fitzpatrick, M. A. (1988). Between husbands and wives: Communication in marriage. Newbury Park, CA: Sage.

Folger, J. P., \& Poole, M. S. (1984). Working through conflict: A communication perspective. Glenview, IL: Scott, Foresman.

Furer-Haimendorf, C. V. (1967). Morals and merits: $A$ study of values and social controls in South Asian Societies. Chicago: University of Chicago Press.

Galtung, J. (1965). Institutionalized conflict resolution: A theoretical paradigm. Journal of Peace Research, 2, 349-397.

Gibbs, J. L. (1963). The Kpelle moot: A therapeutic model for the informal settlement of disputes. Africa, 33, 1-10.

Gluckman, M. (1969). Custom and conflict in Africa. New York: Barnes \& Noble. (Original work published 1956)

Goffman, E. (1959). The presentation of self in everyday life. New York: Anchor.

Granovetter, M. S. (1973). The strength of weak ties. American Journal of Sociology, 78, 1360-1380. 
Gulliver, P. H. (1979). Disputes and negotiations: A cross-cultural perspective. New York: Academic Press.

Hall, J. (1969). Conflict management survey: A survey of one's characteristic reaction to and handling of conflict betu'een himself and others. Monroe, TX: Telemetrics International.

Hocker, J. L., \& Wilmot, W. W. (1985). Interpersonal conflict. Dubuque, IA: Brown.

Kanter, R. M. (1983). The change masters: Innovations for productivity in the American corporation. New York: Simon \& Schuster.

Kapferer, B. (1972). Strategy and transaction in an African factory: African workers and Indian management in a Zambian town. Manchester, England: Manchester University Press.

Kilmann, R. H., \& Thomas, K. W. (1977). Developing a forced-choice instrument. Educational and Psychological Measurement, 37, 309-325.

Knapp, M. L., Putnam, L. L. \& Davis, L. J. (1988). Measuring interpersonal conflict in organizations: Where do we go from here? Management Communication Quarterly, 1 , 414-429.

Koch, K. F. (1974). War and peace in Jalemo: The management of conflict in highland New Guinea. Cambridge, MA: Harvard University Press.

Kolb, D.M. (1988, August). Conflict dramas in organizations: some amendments to theory. Paper presented at the annual meeting of the Academy of Management, Anaheim, CA.

Kolb, D. M., \& Bartunek, J. A. (Eds.). (1992). Hidden conflict in organizations: Uncovering behind-the-scenes disputes. Newbury Park, CA: Sage.

Lawrence, P. R., \& Lorsch, J. W. (1967). Organization and environment. Cambridge, MA: Harvard University Press.

Marsden, P. V., \& Campbell, K. E. (1984). Measuring tie strength. Social Forces, 63, 482-501.

Merry, S. E. (1979). Going to court: Strategies of dispute management in an American urban neighborhood. Law and Society Review, 13, 891-925.

Morrill, C. (1989). The management of managers: Disputing in an executive hierarchy. Sociological Forum, 4, 387-407.

Morrill, C. (1991a). Conflict management, honor, and organizational change. American Journal of Sociology, 97, 585-622.

Morrill, C. (1991b). The customs of conflict management among corporate executives. American Anthropologist, 93, 871-893.

Morrill, C. (1992). The private ordering of professional relations. In D. M. Kolb \& J. A. Bartunek (Eds.), Hidden conflict in organizations: Uncovering behind-the-scenes disputes (pp. 92-115). Newbury Park, CA: Sage.

Nader, L., \& Todd, H. F. (1978). The disputing process: Law in ten societies. New York: Columbia University Press.

Nelson, R. E. (1989). The strength of strong ties: Social networks and intergroup conflict in organizations. Academy of Management Review, 32, 377-401.

Pacanowsky, M. E. \& O'Donnell-Trujillo, N. (1983). Organizational communication as cultural performance. Communication Monographs, 50, 126-147.

Patterson, O. (1982). Slavery and social death. Cambridge, MA: Harvard University Press. Perrow, C. (1986). Complex organizations: A critical essay. New York: Random House.

Pondy, L. R. (1967). Organizational conflict: Concepts and models. Administrative Science Quarterly, 12, 296-320.

Prien, H. (1987). Strategies for third party intervention. Human Relations, 11, 699-720.

Pruit, D., \& Rubin, J. Z. (1986). Social conflict: Escalation, stalemate, and settlement. New York: Newberry Award Records, Inc. 
Putnam, L. L., \& Poole, M. E. (1987). Conflict and negotiation. In F. M. Jablin, L. L. Putnam, K. H. Roberts, \& L. W. Porter (Eds.), Handbook of organizational communication: An interdisciplinary perspective (pp. 549-599). Newbury Park, CA: Sage.

Putnam, L. L., \& Wilson, C. E. (1982). Communicative strategies in organizational conflicts: Reliability and validity of a measurement scale. In M. Burgoon (Ed.), Communication yearbook 6 (pp. 629-652). Beverly Hills, CA: Sage.

Rahim, M. A. (1983). A measure of styles of handling interpersonal conflict. Academy of Management Journal, 26, 368-376.

Rahim, M. A. (1986). Referent role and styles of handling interpersonal conflict. Journal of Social Psychology, 126, 79-86.

Raiffa, H. (1982). The art and science of negotiation. Cambridge, MA: Harvard University Press.

Riggs, C. J. (1983). Dimensions of organizational conflict: A functional analysis of communication tactics. In R. N. Bostrom (Ed.), Communication yearbook 7 (pp. 517-532). Beverly Hills, CA: Sage.

Roberts, S. (1979). Order and dispute. London: Penguin.

Ross, R. G., \& DeWine, S. (1988). Assessing the Ross-DeWine conflict management message style (CMMS). Management Communication Quarterly, 1, 389-413.

Schellenberg, J. A. (1982). The science of conflict. New York: Oxford University Press.

Simmel, G. (1955). Conflict and the web of group-affiliations. New York: Free Press. (Original work published 1908)

Strauss, A. (1978). Negotiations. San Francisco: Jossey-Bass.

Thomas, K. W. (1976). Conflict and conflict management. In M. Dunnette (Ed.), Handbook of industrial and organizational psychology (pp. 889-936). Chicago: Rand McNally.

Thomas, K. W., \& Kilmann, R. H. (1974). Thomas-Kilmann conflict MODE instrument. Tuxedo, NY: Xicom.

Thomas, K. W., \& Kilmann, R. H. (1975). The social desirability variable in organizational research. Academy of Management Journal, 18, 741-752.

Turnbull, C. (1965). Wayward servants: The two worlds of the African pygmies. Garden City, NJ: Natural History Press.

Van Maanen, J. (1988, August). Drinking our troubles away. Paper presented at the annual meeting of the Academy of Management, Anaheim, CA.

Walton, R. E. (1969). Interpersonal peacemaking: Confrontations and third party consultation. Reading, MA: Addison-Wesley.

Weider-Hatfield, D. (1988). Assessing the Rahim organizational conflict inventory-II (ROCI-II). Management Communication Quarterly, 1, 350-366.

White, H. C. (1961). Management of conflict and sociometric structure. American Sociological Review, 67, 185-199.

Womack, D. F. (1988). A review of conflict measurement instruments in organizational settings. Management Communication Quarterly, 1, 437-445. 